\section{Can an Animal Count?}

Sir John LubBock, in his interesting paper on animal intelligence (NATURE, vol. xxxiii. pp. 46-7), virtually puts this question with reference to the dog. But the question whether a dog, or any other animal, can count will depend upon what we mean by counting. In the ordinary and correct signification of the term, counting consists in applying conventional signs to objects, events, \&c., as when we say " one," "two," "three," to the striking of a clock. Clearly in this sense there is no reason to suppose that any animal can count. But there is another sense in which the term "counting" may be used-i.e. as designating the process of distinguishing, with respect to number, between the relative contents of two or more perceptions. While addressing an audience of roo individuals a lecturer can immediately perceive that it does not contain 1000 ; and even without, in the true sense, counting them may make a tolerably close guess at their number. The accuracy of such a guess will depend upon two conditions. The first of these is the number of units to be computed, and the second is the previous practice he may have had in that kind of computation. Thus, every man is able to tell the difference between one and two, two and three, \&c., up to perhaps seven and eight objects or events, without resorting to the expedient of marking off each with a separate sign. But somewhere about this point most persons require to adopt a system of numerical notation, if they desire to be accurate; and probably no one, without either special practice or some such system, could be perfectly sure whether he held eleven or twelve shillings in his hand, or whether a clock had just struck eleven or twelve. Indeed, it is just because of the rapidly-increasing difficulty of thus computing diminishing differences of ratio by immediate perception, that primitive man first lays the foundations of arithmetic by marking off the objects or events upon his fingers and toes. As already indicated, however, special practice makes a great difference in the accuracy with which such instantaneous computation can be made. Several years ago Prof. Preyer, of Jena, tried some experiments upon this subject, and found, if I remember correctly, that after a course of special training one might acquire the power of instantaneously distinguishing between twenty and twenty-one dots promiscuously scattered over a piece of paper.

Now, it is clearly only in this way that animals can be supposed to count at all ; and, therefore, the only question is as to how far they are able to take immediate cognisance of the precise numerical content of a perception-or, in the case of a series of events, how far they are able to take similar cognisance of their past perceptions. But, as Sir John Lubbock observes, there is no record of any experiments having been made in this direction. Houzeau (tom. ii. p. 207) says that the mules used in the tramways at New Orleans are able to count five ; for they have to make five journeys from one end of the tramway to the other before they are released, and they make four of these journeys without showing that they expect to be released, but bray at the end of the fifth. If this is really a case of "counting," in the incorrect sense of the term (and not due to observing some signs of their approaching release), it is probably due to their perception of a known amount of fatigue, a known duration of time, or some other such measure.

Several years ago my sister tried to teach an intelligent terrier to fetch a stated number of similar little woollen balls placed in a box at a distance from herself-the number stated, or ordered, being purposely varied from one to six. But although she is good at teaching animals, and here went to work judiciously in ways which I need not wait to describe, the result, as in the case given by Sir John Lubbock, was a total failure.

My object in making these remarks is to point out that in experiments of this kind the game seems scarcely worth the candle. Even if it were proved that a dog could "count" up to any particular number, all that we should have proved would be that the dog is able to distinguish between the degrees of two or more perceptions of a given kind; we could not thus prove any abstract conception of number on the part of the animal, such as is implied on the part of the "Damara floundering hopelessly in a calculation." Howsoever hopeless such floundering may be if the man is really calculating-i.e. employing some system of numerical signs - his operations are being conducted on a totally different psychological level from those of the bitch who, in surveying her litter of puppies, perceives that there is not so great a mass of them as she remembers to have perceived before. Psychologically considered, the artifice of numerical notation is as far above any such faculty of simple perception, as the artifice of alphabetical writing is above that of simple association. I cannot doubt that a moment's thought would have shown Sir John Lubbock how needless was his precaution-while establishing certain associations of ideas in a dog's mind between written words on a card and the things signified-of spelling the words phonetically, "so as not to trouble him by our intricate spelling."

It is a most interesting fact that a dog's attention can be so far fixed upon written signs that a special association of ideas admits of being established between them and the things signified; but the psychological distance between establishing such a special association and spelling a word is so enormous as not to admit of computation. And similarly, even if my sister had succeeded in teaching her terrier to fetch a stated number of balls at word of command, no one could have supposed that she had thus taught the animal to count, in the sense of employing any system of numerical notation: she would only have proved the degree in which this animal was able to perceive, without counting, the different appearances presented by this, that, or the other volume of balls in a box.

George J. Romanes

\section{Lodge's "Mechanics"}

PERMit me to thank Prof. Tait for his kind and amusing criticism of my little book. I am struck with comic horror at the thought that anything in the preface can be construed into a comparison between works like Thomson and Tait, Clerk-Maxwell and W. K. Clifford, with such elementary picture-books as Deschanel and Ganot. I do not indeed share Prof. Tait's contempt for these "foreign" books; a student will find in them details, about (say) barometers or airpumps, for which he may search the other works mentioned in vain. I did not urge students to read Thomson and Tait, because to those who can the advice is superfluous; to those who cannot it is disheartening. I did, and do, recommend such junior students as we get at provincial colleges to read easy works on Physics-not always because they contain a profound and satisfactory statement of principles, for how few of them do, but because they explain a multitude of details and experimental developments with which it was unwise to encumber a little book dealing mainly with vital principles, and aiming at being, in its humble way, an introduction to the classics of the science.

My book is primarily intended as milk for babes; and while it would be cruel to tell a baby to look at the sun, it is possible to direct his attention to a gas-light with some pleasure and satisfaction.

University College, Liverpool, November I 3

\section{The Resting Position of the Oyster-A Correction}

IN a late number of NATURE (vol. xxxii. p. 597) Mr. J. T. Cunningham makes the extraordinary announcement that Woodward, Jeffrey, and Huxley were wrong in asserting that the oyster rests on the left side. I am in a position to state with positive certainty that it is invariably the left valve of the fry of the oyster which becomes affixed to a foreign object. I have examined thousands of very young adherent spat ranging in size from $\mathbf{I}-9$ oth of an inch to 2 inches in diameter, and have never found an exception to this rule. Besides the positive statements to the same effect made by Huxley and others, I would refer the reader to a brief paper by myself entitled "On the Mode of Fixation of the Fry of the Oyster" (Bull. U.S. Fish Commission, vol. ii., I882, pp. $383-387$ ) ; but I would caution the reader that Figs. 3 to 8 were reversed through an unfortunate oversight, as the apices of the umbos of all the larval shells figured on p. 387 should be directed to the left instead of to the right side. This blunder of the artist is pointed out in the explanation to plate 75, where the figures from the above-cited notice are reproduced in my paper entitled "A Sketch of the Life-History of the Oyster," forming Appendix II. to "A Review of the Fossil Ostreidæ of North America," by Charles A. White, M.D., and Prof. Angelo Heilprin. In another paper of mine, "The Metamorphosis and Post-Larval Development of the Oyster," Rep. U.S. Fish Commissioner, Part 10, for I882, p. 784, Fig. 2 shows the larval shell, $L$, of the young spat in normal position, with the umbo directed to the left. This figure may be compared with advan- 